\title{
Does initial management affect the rate of repetition of deliberate self harm? Cohort study
}

\author{
M J Crawford, S Wessely
}

In the year following presentation to hospital after deliberate self harm, up to $25 \%$ of people repeat the act. ${ }^{1}$ A range of sociodemographic and psychological factors has been shown to predict the likelihood of repetition. ${ }^{2}{ }^{3}$ Factors related to the management of patients may also be important. Observational studies have suggested that some people who receive a psychiatric assessment as part of their initial management may have lower rates of repetition of self harm. ${ }^{4}$ We examined the effect of other aspects of management on rates of repetition among a cohort of patients presenting to medical services after deliberate self harm.

\section{Subjects, methods, and results}

All incidents of deliberate self harm among patients registered with 16 randomly selected general practices in the inner city area of Southwark, south London, were monitored over 18 months. We recorded details of initial psychosocial management and of any subsequent treatment given by hospital accident and emergency services. We compared the characteristics of patients who repeated self harm with those of patients who did not. We then used factors that were related to repetition of self harm to build a multivariate model. Finally, we used Cox's regression to calculate adjusted hazard ratios for repetition of self harm among groups of patients receiving different forms of treatment.

In all, 324 patients deliberately harmed themselves. We excluded 16 patients from the study because detailed data on their management were not available owing to missing handwritten notes in the accident and emergency department. Of the remaining 308 patients, 14 were treated either by their general practitioner or by mental health services and were never assessed in the accident and emergency department. Of the 294 patients seen in the accident and emergency department, 34 discharged themselves before assessment had been completed, 199 were referred by accident and emergency staff for psychiatric assessment, and 61 were discharged after initial assessment. After initial management, 103 of the 308 patients received follow up care from mental health services, the rest being treated entirely in primary care. Fifty four patients repeated self harm during the 18 months; they were more likely to have had a history of deliberate self harm (hazard ratio $=4.3,95 \%$ confidence interval 2.0 to 9.0 ) and of substance misuse (2.0, 1.1 to 3.7) than those who harmed themselves only once during the 18 months. The table shows the hazard ratios for repetition adjusted for the effects of history of self harm and of substance misuse among those receiving different aspects of initial management. Patients who discharged themselves from the accident and emergency department before completion of initial assessment had three times the rate of repetition of self harm as those who completed the initial assessment.

Hazard ratios (95\% confidence intervals) associated with repetition of deliberate self harm among 308 patients treated after deliberate self harm

\begin{tabular}{|c|c|c|c|}
\hline \multirow[b]{2}{*}{$\begin{array}{l}\text { Aspect of initial psychosocial } \\
\text { management }\end{array}$} & \multirow{2}{*}{$\begin{array}{c}\text { No }(\%) \\
\text { who } \\
\text { repeated } \\
\text { self harm }\end{array}$} & \multicolumn{2}{|r|}{ Hazard ratio } \\
\hline & & Unadjusted & $\begin{array}{l}\text { Adjusted for history of self harm } \\
\text { and substance misuse }\end{array}$ \\
\hline $\begin{array}{l}\text { Attended accident and emergency } \\
\text { for initial assessment }(n=294)\end{array}$ & $52(18)$ & $1.7(0.4$ to 7.1$)$ & 2.6 (0.6 to 10.6$)$ \\
\hline $\begin{array}{l}\text { Self discharge from casualty } \\
\text { before completion of initial } \\
\text { assessment }(n=34)\end{array}$ & $13(38)$ & 3.3 (1.7 to 6.4$)$ & 3.0 (1.4 to 6.1$)$ \\
\hline $\begin{array}{l}\text { Assessed by psychiatrist or } \\
\text { specialist nurse before } \\
\text { discharge }(n=199)\end{array}$ & $32(16)$ & $1.1(0.6$ to 2.0$)$ & $1.3(0.5$ to 3.4$)$ \\
\hline $\begin{array}{l}\text { Follow up from psychiatry services } \\
(n=103)\end{array}$ & $21(20)$ & $1.2(0.7$ to 2.2$)$ & $1.2(0.7$ to 2.3$)$ \\
\hline
\end{tabular}

\section{Comment}

This study shows that patients who discharge themselves before completing initial management have a considerably increased rate of repetition. This observation is of special concern because local evidence suggests that the proportion of people who discharge themselves from hospital before their initial assessment has been completed has more than doubled over recent years (from $8 \%$ in 1991 to $17 \%$ in 1997). At a time when evaluation of interventions for patients who deliberately harm themselves is taking place, it is of concern that among those who are being excluded from studies (because they discharge themselves before initial management is completed) may be some patients at greatest risk of repeating self harm. These findings emphasise the importance of optimising the psychosocial management by staff in accident and emergency departments during the initial stages of treatment ${ }^{5}$ and the need to develop further understanding of the reasons why many choose to leave hospital before management has been completed.

We thank Nicola Leete for help with data collection.

Contributorship: MJC formulated the hypothesis for the study, collected the data, conducted the analysis, and led in the writing of the paper. SW initiated the research and contributed in the writing of the paper. MJC will act as guarantor for the paper.

Funding: MJC was funded by a training fellowship from the Bethlem and Maudsley NHS Trust.

Competing financial interest: None declared.

1 Platt S, Hawton K, Kreitman N, Fagg J, Foster J. Recent clinical and epidemiological trends in parasuicide in Edinburgh and Oxford: a tale of two cities. Psychol Med 1988;18:405-18.

2 Owens D, Dennis M, Read S, Davis N. Outcome of deliberate self poisoning. An examination of risk factors for repetition. $\mathrm{Br} J$ Psych 1994:165:797-801.

3 Scott J, House R, Yates M, Harrington J. Individual risk factors for early Scott J, House R, Yates M, Harrington J. Individual risk factors for
repetition of deliberate self harm. Br J Med Psychol 1997;70:387-93.

4 Hawton K, Fagg J. Trends in deliberate self poisoning and self injury in Oxford 1976-90. BMJ 1992;304:1409-11.

5 Crawford MJ, Turnbull G, Wessely S. Deliberate self harm assessment by accident and emergency staff-an intervention study. J Accid Emerg Med $1998 ; 15: 18-22$.

(Accepted 6July 1998)
Section of Epidemiology and General Practice, Institute of Psychiatry, London SE5 8AZ

M J Crawford, research fellow Department of Psychological Medicine, King's College Hospital, London SE5 9RS S Wessely, professor of liaison psychiatry

Correspondence to: Dr M J Crawford sphamjc@iop. bpmf.ac.uk

BMJ 1998;317:985 